\title{
Hypereosinophilia Induced by Lung Adenocarcinoma: A Rare Case
}

Yusuf Kayar $^{1^{*}}$, Birol Baysal ${ }^{1}$, Nuket Bayram Kayar ${ }^{2}$, Nang Hseng Kyio ${ }^{3}$, Nabila Mahdi ${ }^{3}$, Nurcan Unver ${ }^{4}$, Huseyin Kadioglu ${ }^{5}$ and Ahmet Danalioglu ${ }^{1}$.

${ }^{1}$ Department of Gastroenterology, Faculty of Medicine, Bezmialem Vakif University, Istanbul, Turkey

${ }^{2}$ Department of Family Medicine, Bagcilar Education and Research Hospital, Istanbul, Turkey

${ }^{3}$ Department of Internal Medicine, Faculty of Medicine, Bezmialem Vakif University, Istanbul, Turkey

${ }^{4}$ Department of Pathology, Faculty of Medicine, Bezmialem Vakif University, Istanbul, Turkey

${ }^{5}$ Department of General Surgery, Faculty of Medicine, Bezmialem Vakif University, Istanbul, Turkey

*Corresponding author: Yusuf Kayar, MD, Gastroenterology Clinic of Bezmialem Vakıf University, Istanbul 34093, Turkey, Tel: +90 2125332326 ; Fax: +90 505 564 70 67; E-mail: ykayar@yahoo.com

Rec date: Jan 13, 2015, Acc date: Feb 25, 2015, Pub date: Feb 27, 2015

Copyright: (c) 2015 Kayar Y, et al. This is an open-access article distributed under the terms of the Creative Commons Attribution License, which permits unrestricted use, distribution, and reproduction in any medium, provided the original author and source are credited.

\begin{abstract}
Eosinophilia is observed in allergic and atopic diseases such as asthma, allergic bronchopulmonary aspergillosis, atopic dermatitis, drug reactions, eczema, episodic angioedema and urticarial, in idiopathic eosinophilic syndrome, connective tissue diseases, vasculitis, granulomatous diseases, parasitic and nonparasitic infections, skin diseases and various pathologies such as hematological malignancies. The association between malignancy and eosinophilia has been identified especially in hematological and lymphocytic cancers. However, it is very rare in solid cancers. In bronchial carcinomas, regardless of the histological type, eosinophilia is very rarely observed. Here, we present a case with apparent eosinophilia induced by lung adenocarcinoma.
\end{abstract}

Keywords: Lung carcinoma; Eosinophilia; Solid malignancy; Leukemoid reaction

\section{Introduction}

The association between malignancy and eosinophilia has been identified especially in hematological and lymphocytic cancers. However, it is very rare in solid cancers [1]. Apparent eosinophilia is usually seen in uterus, breast, thyroid, adrenal, gallbladder and colon carcinomas [2]. In bronchial carcinomas, regardless of the histological type, eosinophilia is very rarely observed [1]. Eosinophilia can form as a result of paraneoplastic syndrome. Herein, we present a case of lung adenocarcinoma found with eosinophilia.

\section{Case Report}

64-year-old male patient presented with dry cough and shortness of breath for a month. He was diagnosed with pneumonia and started on antibiotics. However, his symptoms did not resolve. So he was admitted to the our clinic. He has not chronic diseases. His past medical history and family history was unremarkable. There was no history of smoking, alcohol consumption and environmental exposures. On chest auscultation there were coarse breath sounds especially on the right side with prolonged expiratory phase, and widespread rhonchi was heard as well. The rest of the physical examination was unremarkable. Laboratory findings were as follows: Blood urea nitrogen: $8 \mathrm{mg} / \mathrm{dl}$, Creatinine: $0.7 \mathrm{mg} / \mathrm{dl}$, Uric acid: 4.7 mg/dl, Leukocyte: 45.990 cells/ $\mu$ l, Hb: 15.1 g/dl, Hct: 46 \%, MCV: 88, MCHC: 32, PLT: 274.000 cells/ $\mu \mathrm{l}$, Neutrophil: 25.350 cells $/ \mu \mathrm{l}$, Monocyte: 3.250 cells/ $\mu$ l, Eosinophil: 11.700 cells/ $\mu l$. Liver enzymes and $\mathrm{LDH}$ in normal ranges. IgE level was $2379 \mathrm{IU} / \mathrm{ml}$. His oxygen saturation was $91 \%$ on room air. He was given $2 \mathrm{lt} / \mathrm{minute}$ nasal oxygen. Chest Computer Tomography $(\mathrm{CT})$ revealed $73 \times 61 \mathrm{~mm}$ noduler lesion with cavitation on the superior segment of the right lower lobe. Metastatic nodules were detected on lungs bilateraly, the biggest being $67 \times 30 \mathrm{~mm}$ (Figure 1). On positron emission tomography (PET) CT, hypermetabolic malignant mass on the right lower lobe and bilateral metastatic nodules. Since the patient's general condition was not good and his oxygen saturation was low, bronchoscopy could not be performed. The result of sputum cytology that was sent three days in a row was reported as adenocarcinoma. Eosinophilia was detected on the peripheral smear. No atypical cells were seen (24\% eosinophilia, 6\% lymphocyte, 5\% monocyte, $65 \%$ neutrophil) (Figure 2A). Bone marrow aspiration was reported an increase on the eosinophilia count (Figure 2B). Fecal parasite was negative regarding eosinophilic etiology. The patient had no history of allergic and atopic diseases. All acute and chronic infectious diseases that can cause hypereosinophilia were excluded. No pathology regarding collagen tissue disease and vasculitis was detected. All other solid and hematological malignancies except lung cancer were ruled out. Drug reactions were not considered to be the cause of leukocytosis and hypereosinophilia since these findings antedated antibiotic intake history. So it was evaluated as leukemoid reaction and eosinophilia induced by lung malignancy. As the patients general condition was poor, no treatment could be prescribed. The patient's general condition gradually worsened and he died on the third week of his hospitalization.

\section{Discussion}

Eosinophilia is observed in allergic and atopic diseases, dressler syndrome, eosinophilic fasciitis, idiopathic eosinophilic syndrome, inflammatory bowel disease, vasculitis, granulomatous diseases, adrenal insufficiency, immunodeficiency syndromes, parasitic and nonparasitic infections, dermatitis herpetiformis, skin diseases such as exfoliative dermatitis, pemfigus, psoriasis and various pathologies such as hematological malignities [2]. Eosinophilia is observed in various 
lung diseases along with pulmonary infiltrates [3]. However, eosinophilia is rarely detected in solid malignancies [4].

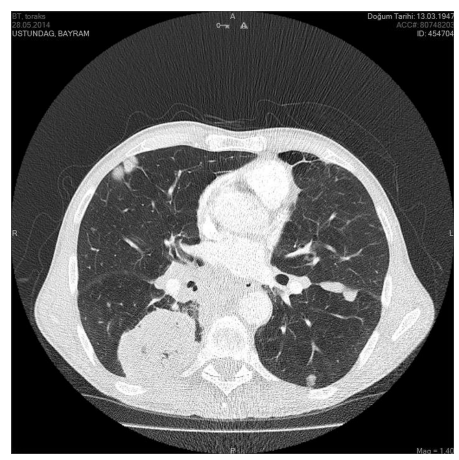

Figure 1: The nodular lesion sized $73 \times 61 \mathrm{~mm}$ showing cavitation were observed in the superior segment of the right lower lobe. The metastatic nodules were observed in the left and right lung, the biggest being $67 \times 30 \mathrm{~mm}$.

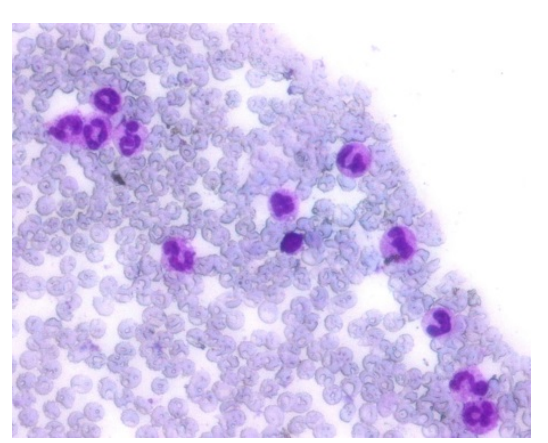

Figure 2A: Eosinophilia was detected on the peripheral smear.

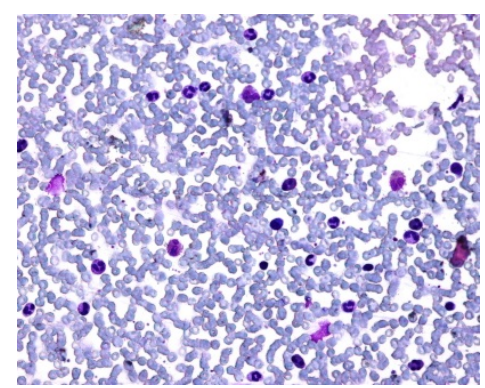

Figure 2B: Eosinophilia was detected on bone marrow aspiration.

Lung malignancies can be seen with paraneoplastic syndrome such as ADH syndrome, cushing syndrome, carcinoid syndrome especially associated small cell lung cancer, hypercalcemia especially associated squamous cell lung cancer and gynaecomastia especially associated large-cell lung carcinoma. Although lung adenocarcinoma is rarely associated with hypereosinophilia [3-5].

Peripheral blood eosinophilia is observed in $0.5 \%$ of all malignant pathologies as it was defined for the first time in 1893 by Rheinbach.
Eosinophil count can be useful in differentiation of benign and malign lesions. An increase in eosinophil count can be suggestive of bad prognosis [6]. Several factors might contribute to eosinophilia. Wasserman et al. and Kay et al. defined active substances such as low molecular weight eosinophil chemotactic factor of anaphylaxis (ECFA) in anaplastic squamous cell carcinoma of the lung in lymph node cells and anaplastic large cell carcinoma tissue in 1974 and 1975. Goetz et al. defined the same in both tumor tissue and peripheral blood in 1978 [7]. Glungard et al. isolated a glycoprotein that had a strong eosinophil colony stimulating factor effect in bone marrow cultures in a lung cancer case with peripheral blood eosinophilia in 1983 [8]. Mahmoud et al. also defined that eosinophilic protein which is probably derived from lymphocytes and is responsible of eosinophilic response to parasitic infections $[1,2,8]$.

The mechanism of eosinophilia in patients with lung cancer is not known completely. The first investigations aimed to explain eosinophilia with the necrosis of tumorous tissue, protein products causing eosinophilotactic response, bone marrow metastases as a result of the stimulation of eosinophil production, vagal reflex and familial eosinophilic predisposition [3,5]. Subsequently, these types of tumours were thought to contain colony stimulating factor and eosinophil colony stimulating factor or both $[6,7,8]$. Another view is that antigens produced by a tumour can cause an isolated eosinophilia through sensitization or leukemoid reactions such as neutrophilia or leucocytosis can lead to eosinophilia $[4,9]$. In addition, morphological changes such as eosinophils having vacuoles or granules was thought to cause eosinophilia by extending the life span of the cells [10].

In the studies, it was reported that some tumors have tumoricidal effects and secrete eosinophilactic substances which extends life expectancy; however, it was also reported that eosinophilia may lead to early deaths by causing tissue destruction and especially endomyocardial fibrosis [1,6,10]. In many cancer patients with eosinophilia, it is reported that cancer may show a very fast progress and there might be no time left for the eosinophils to cause cardiac destruction [2]. As in our patient cancer progress was very fast, he died in a short time without developing cardiac failure.

\section{Conclusion}

Although hypereosinophilia is commonly seen in allergic diseases and parasitic infections, malignancy should also be considered as one of differential diagnosis of hypereosiniphilia. The most important causes of eosinophilia in patients with lung cancer is the increment in eosinophil formation in the bone marrow and increase in the eosinophilic factor formation, which extends the life span of eosinophils. Patient with lung cancer who have eosinophilia tend to have more progressive disease with shorter survival.

\section{References}

1. Remacle P, Bruart J, Henneghien C (1988) Bronchial cancer and hypereosinophilia. Eur Respir J 1: 191-192.

2. Beeson PB (1983) Cancer and eosinophilia. N Engl J Med 309: 792-793.

3. Rochester CL (1998) The eosinophilic pneumonias. In: Fishman AP, Elias JA, Fishman JA (eds.) Fishman's Pulmonary Diseases and Disorders. New York: Mc Graw Hill Book Company: 1133-1135.

4. Seaton A, Seaton D, Leitch AG (1989) Cancer of the lung. In: Crofton and Douglas's Respiratory Disease. Boston: Blackwell Scientific Publications 912-975.

5. Lo CH, Jen YM, Tsai WC, Chung PY, Kao WY (2013) Rapidly evolving asymptomatic eosinophilia in a patient with lung adenocarcinoma causes 
Citation: Kayar Y, Baysal B, Kayar NB, Kyio NH, Mahdi NM, et al. (2015) Hypereosinophilia Induced by Lung Adenocarcinoma: A Rare Case. J Carcinog Mutagen 6: 216. doi:10.4172/2157-2518.1000216

Page 3 of 3

cognitive disturbance and respiratory insufficiency: Case report. Oncol Lett 5: 495-498.

6. Knox AJ, Johnson CE, Page LE (1986) Eosinophilia associated with thoracic malignancy. Br J Dis Chest 80: 92-95.

7. Goetzl EJ, Tashjian AH Jr, Rubin RH, Austen KF (1978) Production of a low molecular weight eosinophil polymorphonuclear leukocyte chemotactic factor by anaplastic squamous cell carcinomas of human lung. J Clin Invest 61: 770-780.

8. Slungaard A, Vercellotti G, Zanjani E, Ascensao J, Jacob HS (1982) Tumor-induced eosinophilia and endocardial fibrosis: evidence for ectopic eosinophilopoietin production and toxic $\mathrm{O} 2$ metabolite-mediated endothelial damage. Trans Assoc Am Physicians 95: 8-11.

9. Ascensao JL, Oken MM, Ewing SL, Goldberg RJ, Kaplan ME (1987) Leukocytosis and large cell lung cancer. A frequent association. Cancer 60: 903-905.

10. Kay AB (1984) Eosinophils. In: Bienenstock J (eds.) Immunology of the lung and upper respiratory tract. New York: Mc Graw Hill Book Company: 139-157. 